\title{
Towards Developing an Edible Fungi Factory HACCP MIS Base on RFID Technology
}

\author{
Wang Yunsheng ${ }^{1}, \mathrm{Xu}$ Shipu ${ }^{1}$, Wan ChangZhao ${ }^{1}$, Cheng Jihong ${ }^{2}$, Guo Qian ${ }^{3}$, \\ Yang Juan ${ }^{1}$, and Zhao Jingying ${ }^{1, *}$ \\ ${ }^{1}$ Technology \& Engineering Research Center for Digital Agriculture, Shanghai Academy of \\ Agricultural Sciences, Shanghai 201106, China \\ ${ }^{2}$ Shanghai Finc Bio-tech Inc, Shanghai 201401, China \\ ${ }^{3}$ Institute of Edible Fungi, Shanghai Academy of Agriculture \\ Sciences, Shanghai 201106, China \\ zjy@saas.sh.cn
}

\begin{abstract}
According to the low yield of edible fungus and the poor quality of edible fungi in factory, the production management situation in edible fungi factory was analyzed. Then the solution of edible fungi factory HACCP(Hazard Analysis Critical Control Point) MIS(management information system) based on RFID(Radio Frequency Identification) technology was presented. Edible fungi production process by the hazard analysis to determine the raw materials, burden mix materials and bottling, inoculation, culture, and growth as the critical control points. For each critical control points, respectively, to develop appropriate critical limits, clearly defined monitoring objects, methods, frequency and corrective measures, critical control point of information collection for the use of RFID technology. Through the implementation of HACCP MIS, edible fungi yield and quality have improved.
\end{abstract}

Keywords: edible fungi factory, HACCP, MIS, RFID.

\section{Introduction}

Edible fungi factory mode of production in the 1970s originated in Japan, it is a biotechnology, automation engineering, information technology, eco-technology, processing maintaining freshness technology in one integrated system [1]. Industrial production of edible fungi is a traditional agricultural and modern industrial production of a product of the combination with the characteristics of industrial production, production targets at the same time it is with life. Industrial production of edible fungi and the development of advanced scientific and technological progress, as well as the development of special equipment and use, making the form of the production of great changes have taken place to achieve seasonal hand from the original workshop production of the anniversary of the modern industrial-scale supply changes in production methods [7]. Since the 1990s, factory production of edible fungi in China have been developing rapidly and has now become in the world the biggest edible fungus producer country and exporter country [4], the edible fungus output value is situated sixth in the crop production [12]. Edible fungi production technology has

${ }^{*}$ Corresponding author. 
brought production management to new issues and challenges: how to improve the quantity and quality of edible fungi products, ensure food safety.

The Pillsbury Company encountered this dilemma in the 1960s in its attempts to fulfill several food production contracts with the US Army and the National Aeronautics and Space Administration (NASA). NASA in particular had very stringent microbiological acceptance criteria, not wanting to risk the illness of an astronaut during a space mission (what an inopportune time for a "two-bucket" illness!). In essence, nothing short of $100 \%$ product testing could assure NASA that a particular packet of food was safe to consume. It was obvious to all involved that product testing could not be used to guarantee food safety. A much better system of food safety assurance was required.

Thus, the genesis of the HACCP concept, a joint development by The Pillsbury Company, the US Army, and NASA. Unlike QC systems, HACCP is a preventive system in which food safety can be designed into the product and the process by which it is produced. It is a system of product design and process control. The HACCP system of food safety is very active at controlling identified hazards. Most importantly, it does not rely upon product testing to assure food safety. Over the next three decades, the HACCP system spread into the food processing industry of the US, and into other countries [13].

At present, some Chinese edible fungi production factory have passed the HACCP system certification, but the lack of security on the impact of edible fungi of the various critical control points of information for automatic acquisition, quality control in artificial acquisition, the text records stage, the impact of the implementation of the HACCP system. It is therefore based on the RFID technology of production of edible fungi HACCP intelligent monitoring system, to improve production efficiency and produce safe and high quality agricultural products are of the significance.

RFID radio frequency identification technology is in the 1990s began to rise an automatic recognition technology, is a RF signal through spatial coupling (alternating magnetic field or electromagnetic field) implementation of the non-contact information is passed, and do pass it to achieve the objective recognition technology. In industrial automation control, the RFID technology has been widely used [8], it can meet modern industrial production in the process of information uniquely identifying the needs of article uniqueness, you can use to monitor the product in the various processes in the status of implementation of the total quality product tracking, mastering the operations of the finished records and parts of the installation of the record, after sales maintenance records for more information, such as refrigerator manufacturing [10], automobile production [11] and so on; you can start from the item the production process of instockroom per conjections data to be accurate, timely of acquisition and recording, processing, and timely feedback from instockroom to grasp items online, in products, methylpyrrolidine, outstockroom of State and location, and implementation of the item's track and on the implementation of the plan steps strict control.

HACCP MIS system and the integration of RFID technology can improve the realtime data acquisition CCPs, the HACCP MIS system to improve quality control on the credibility of the entire software system to improve sensitivity, improve data accuracy; also can be dynamically updated or rewritten in the packaging or the label information, that does not need manual intervention, or do not have to be completed in 
the visual environment of the scanning of product information, can provide the service process to further simplify and the automated tool [2,3].

\section{Edible Fungi Factory Production Process}

Edible fungi factory production process can be divided into pre-vaccination, inoculation and mycelial growth and fruiting the three links, respectively, corresponding to the places of production workshops, inoculation rooms and mushroom houses, the basic process shown in Fig 1. More edible fungi factory production, will every aspect of the final product quality and production of edible fungi have a decisive impact [11].

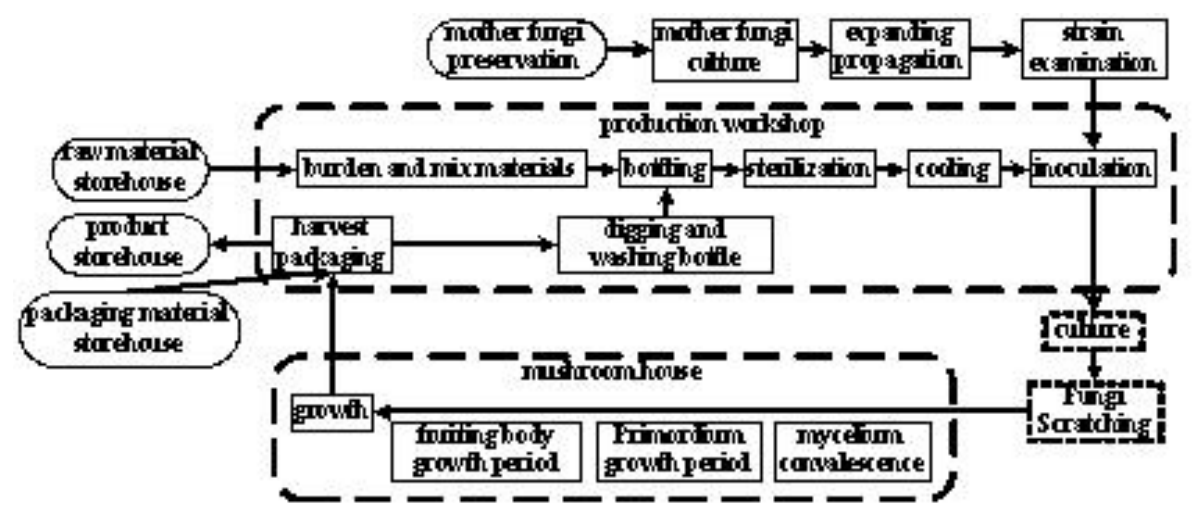

Fig. 1. Put a figure in a "Figure" style, followed by a "Figure Caption"

\section{Edible Fungi Factory Production Quality Management Needs Analysis}

Industrial production of edible fungi production and management of the main problems is rooted in the manual method of data collection, production workshop, inoculation room, mushroom house and other data mainly paper-based carrier, and its record is mainly manual records. Industrial production of edible fungi are widespread information and records management manual mass automatic access to environmental information and preservation of the issue cannot be matched, with advanced methods of data collection is to enhance the production of edible fungi factory management level of the principal means of RFID technology and its production and management systems in the following areas:

\subsection{Real-Time Status of the Batch in the Products}

Need to be able to achieve the quality of the real-time monitoring, the quality of automatically generated reports, the quality of statistics on the cause of the problem occurred and those responsible; to keep abreast of the current link in the production of 
products for each batch in the number of products, realizes the goods in process quantity report form accurate statistics.

\subsection{On the Production Process to Achieve Monitoring and Correction of Deviation from the Threshold}

Monitoring mixes the material and Culture Collection training and so on, need to know specifically what a batch of edible fungi in the growth of the current state of how the growth of environmental conditions, has deviated from the threshold, the need for corrective adjustment.

\subsection{Real-Time Understanding Production Schedule}

To keep abreast of current edible fungi production in every link of production, as well as each production link's to be whether balanced, personnel's of assignment is whether reasonable, whether needs to carry on the production scheduling and the follow up mission arrangement.

\subsection{Reduces the Workshop and the Mushroom Room Management Workload}

Realizes the management carefully, records each Production workshop and the mushroom room edible fungi production situation promptly, in order to carries on the contrastive analysis with the control system record's capacity for large real-time environmental data, realizes the prompt statistics to each kind of report form, reduces the workshop and the mushroom room management workload.

\section{CCPS and Their Corresponding Threshold}

Industrial production of edible fungi in the use of a large number of automation equipment, such as the automatic bottling machine, the vaccination machine, mushroom house control equipment, automatic air conditioning and humidifier, any equipment failures may affect the product quality and safety [9]. Shanghai Finc Bio-tech lnc. is mainly engaged in Hypsizgus marmoreus cultivation factory production, has been through ISO9001: 2000 certification, constructed the GMP Production workshop, has established the HACCP system, and Table 1 for the critical control points and the threshold. RFID based on the HACCP MIS factory production of edible fungi have been the whole process of monitoring, including information on raw materials, the operator, operation date, process technological parameter, deviation information, product character, products batch excellent rate, fraction defective and delivery inspection situation. Key to affect the product quality security the key aspect to set up corrected an error automatically the reset function, and the product entire production process prompt unmistakable record, to produce the superintendent to provide promptly the ideal management tool, also has provided the important basis for the product post-sale quality follow-up and the data analysis [1]. 
Table 1. Critical Control Point and the threshold

\begin{tabular}{|c|c|c|}
\hline CCP No. & Name & threshold \\
\hline CCP 1 & $\begin{array}{l}\text { Annual inspection of raw materi- } \\
\text { als situation }\end{array}$ & Record \\
\hline CCP 2 & Bottled water & $63 \%-65 \%$ \\
\hline CCP 3 & $\mathrm{PH}$ value of bottling & $6-6.8$ \\
\hline CCP 4 & The average weight of bottling & $625-650 \mathrm{~g}$ \\
\hline ССР 5 & Mixing temperature & $118-121^{\circ} \mathrm{C}$ \\
\hline ССР 6 & Sterilization time & $10 \mathrm{~min}$ \\
\hline CCP 7 & $\begin{array}{l}\text { Culture contamination rate of the } \\
\text { Housing }\end{array}$ & $1 \%$ \\
\hline CCP 8 & Scratch fungi water & $1 \mathrm{~cm}$ \\
\hline $\mathrm{CCP} 9$ & $\mathrm{PH}$ value of fungi to scratch & $5.5-6.0$ \\
\hline ССР 10 & $\begin{array}{l}\text { The ninth day reminder lei } \\
\text { (sensory) }\end{array}$ & Record \\
\hline ССР 11 & $\begin{array}{l}\text { Cover mushrooms tumor } \\
\text { (incidence) }\end{array}$ & Record \\
\hline ССР 12 & Storage temperature & $2-5^{\circ} \mathrm{C}$ \\
\hline CCP13 & Fresh air filter case & Record \\
\hline ССР 14 & Colony growth & Record \\
\hline ССР 15 & $\begin{array}{l}\text { Uniformity (scratch bacteria } \\
\text { first } 16 \text { days of total fruiting } \\
\text { situation) }\end{array}$ & Record \\
\hline
\end{tabular}

\section{Edible Fungi Factory Production Quality Management Needs Analysis}

This According to the edible fungi factory production's characteristic, proposed based on RFID technical HACCP MIS solution. The system mainly carries on the quality control and the production schedule control, but also involves the productive plan management, the workshop management, the mushroom house management, the man management and so on, needs to carry on the massive essential data handle work. As shown in Fig. 2. 


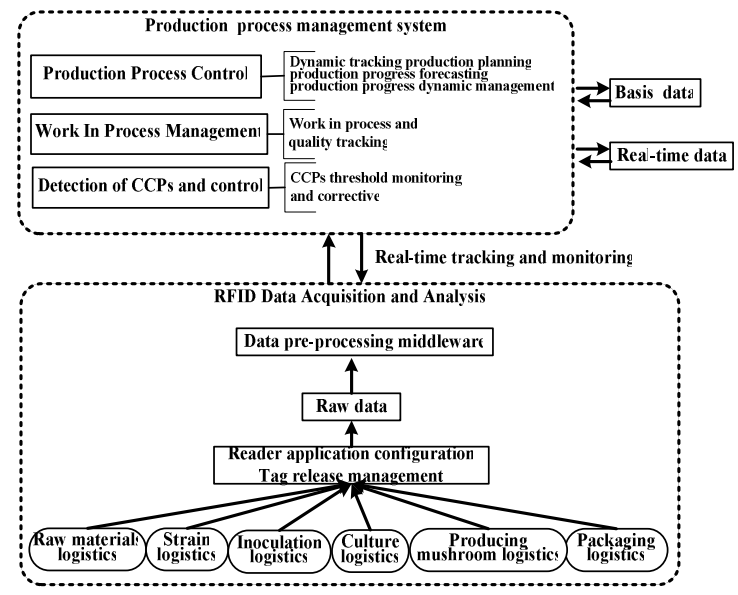

Fig. 2. Structure of edible fungi factory HACCP MIS based on RFID

\subsection{RFID Application}

The RFID applications are mainly located at the bottom of HACCP MIS; face the workshop level's production process, coupled with the sensor indicators on the threshold of CCPs for the collection and recording. It emphasized that the refinement and implementation of HACCP, controls the workshop production process, the management of products, protection of the quality and safety of edible fungi. The overall goal of RFID-based HACCP MIS is to enable enterprise managers and workers will be able to timely and accurate grasp of the production of edible fungi, edible fungi of the quality and safety of the situation, the main links are as follows:

\subsubsection{RFID Tags Issued}

In the beginning of links, for each batch of raw materials paid by an RFID tag, according to different sources of raw materials, different types, different quality standards and other information written to the RFID tags and database; the beginning of the mother fungi preservation of relevant information will be written into the RFID tag and the database; After the bottling, the turnover box as a unit for issuing an RFID tag, will each box edible fungi cultivation information write to the RFID tags and database, write the information, including production dates, types of raw materials, raw material batch, formula type, vaccination information, edible fungi scratching information, growth information.

\subsubsection{Production Link Record}

In workshop or a mushroom house access place establishment a long-range RFID reader, once the raw materials, mother fungi or the turnover box with RFID tags to get into the area, RFID reader will be able to automatically written to RFID tags and automatically recorded the beginning time and relevant information.

\subsubsection{Production Process Information Record}

In warehouses, burden and mix materials workshops, bottling workshops, sterilization room, inoculation room and so on, set of long-range RFID reader, when this place has 
the products in process with RFID tag enters, RFID reader will be able to automatic recording the time of completes the work in the database and the related information. Manually issuing RFID tags before the raw materials into the warehouses, and other links using a turnover box be fixed RFID tags, without additional manual operation, it can be achieved on the production process of the logistics and the quality monitoring, the monitoring granularity may achieve the box level.

\subsection{The Edible Fungi Factory the CCPs Management and the Quality Control}

HACCP system made a series of effects of edible fungi product safety, health, and quality control of CCPs, including requirements relating to the use of materials, water safety, production environmental conditions, such as heavy metal content of raw materials, process parameters temperature, humidity, $\mathrm{CO}_{2}$ concentration , the water content of raw materials, $\mathrm{pH}$ and so on, real-time monitoring and controlling, product traceability records management, were all of the need for supervision, and the CCPs need to cyclical records, large data, through the complete record of man-made and often lags behind some of the information, the impact of the decision-making and the timeliness of corrective action.

HACCP MIS for the management of the various batches of product CCPs, including batch management, CCPs management, CCPs threshold, history records inquiry and so on functions. Users can set up in accordance with the lot numbers of products critical control points and control point threshold, automatic monitoring of control points, if in the production process, the control point value more than threshold, the system immediately report to the user, at the same time to start correcting control system automation. The system can reduce the workload of the quality of management, reduce the production and the quality control cost.

\subsection{Quality Traceability}

Through HACCP MIS application, in production management module establishment batches of product information management, in the software sorting each batches of product according to the production date, to the parameters of each process to monitor, record and statistics, and statistical data timely input into the system, simultaneously it the deviation which and the correcting an error event has in the production process, saves automatically to this product file, forms the complete production process file. This provides with convenient channels and the most convenient tool. And the realization of the production quality traceability, enhanced the product quality confidence level, but also lets the consumer be able to feel relieved.

\subsection{Monitoring of Environmental Parameters}

The environment parameter refers to edible fungi habitat each kind of parameter, including the temperature, the humidity, $\mathrm{CO}_{2}$ and the strength of illumination and so on, the output result indicated by the concrete value and the curve diagram form, clear perspicuity. And may act according to the time selection historical situation parameter record, the early alarm management including the environment alarm range setting, the environment exceptionally reports to user, alarm record processing, alarm record 
inquiry. Moreover, this module also has the establishment to allow the environment parameter variation range, when the environment parameter variation surpasses the range scope or has the unusual circumstance, the system will report to the user. The environment monitoring reduced the manual monitor workload, avoids error which the manual control produces, enhances the early alarm the accuracy.

\subsection{Production Environment Monitoring}

The use of cameras will be the state of production and the environment in real-time photography, video streaming through the signal transmission to control room server, and in accordance with the actual situation in the production workshop, adjustment photography angle and focal distance. Through video monitoring, production management personnel may in the control room examine that each workshop the production situation, to reduce the scene contact's frequency, to reduce the workload, improve efficiency.

\section{Conclusion}

RFID technology has developed rapidly in recent years, the RFID technology's application was already getting more and more widespread, the RFID equipment technology mature and the cost reduced causes to use in the RFID technology Production enterprise's informationization managing massively into the possibility. The edible fungi production process management to the edible fungi yield, the quality and safety is critical [5, 15], but whether obtains the edible fungi production process related real-time data is the key.

The HACCP MIS based on RFID has been used in the industrial production of edible fungi, which monitor the process of production to ensure production stability, provide protection to increase productivity, the HACCP MIS development and the application has solved the agricultural product production quality security problem to a great extent, to improve the comprehensive competitiveness of agricultural products, increase agricultural productivity and reduce production costs.

MIS is composed of the human and the computer, to manage information collection, transmission, storage, processing, maintenance and use, the information acquisition method usually needs to be artificially auxiliary. This article studies is the establishment in management information system's foundation to the edible fungi production, has carried on the expansion to information acquisition's way, proposed based on RFID HACCP MIS solution, can real-time and automatic collect information, based on RFID technical management system carries on effectively all-the-way tracking and to plans the execution step to carry on the strict control, safeguards the edible fungi product safety and realizes the product quality safety to trace.

System in the application that there are imperfections, along with the deepening of the application, needs to make the adjustment unceasingly according to the edible fungi factory production actual situation.

\section{Acknowledgements}

This study was supported by Science and Technology Commission of Shanghai Municipality Program (073919103). 


\section{References}

1. Cheng, J., Chen, C., Li, J.: Development and Application of HACCP Intelligent Control Systerm on Edible Fungus Factory Produc Chinese. Agricultural Science Bulletin 24(2), 449-454 (2008)

2. Dai, Q., Luo, T.: Produce Pursuing and Management System Based on RFID. Computer \& Telecommunication 7, 10-15 (2006)

3. Fu, Z.: Manage Parts Being Manufactured Dynamically to Improve the Comprehensive Management Level on the Spot. Value Engineering 7, 73-76 (2003)

4. Hu, Y., Li, P., Yuan, J.: Exploitation on Industrialized Production Pattern for Edible Fungi. Journal of Anhui Agricultural Sciences 35(9), 2606-2607, 2669 (2007)

5. Huang, Y.: Edible fungus factorization facility cultivation question and countermeasure. Edible Fungi 6, 3-5 (2003)

6. Kim, Y., Moon, M., Yeom, K.A.: Framework for Rapid Development of RFID Applications. In: International Conference on Computational Science and Its Applications, pp. 226-235 (2006)

7. Nie, H., Liu, C., Li, X.: Introduction to the Industrial Productive Approaches of Edible Fungi. Edible Fungi of China 6, 12-14 (2006)

8. Rajagopalan, S., Swaminathan, J.M.: A Coordinated Production Planning Model with Capacity Expansion and Inventory Management. Management Science (11), 1562-1582 (2001)

9. Savage, R.A.: Hazard Analysis Critical Control Point: A Review. Food Reviews International, NAL/USDA 11(4), 575-595 (1995)

10. Tian, M., Ding, X., Shi, S., et al.: RFID technology based on the production line of digital research. Journal of Computer Applications (12), 327-329 (2006)

11. Wang, C., Shao, M., Zhang, X., et al.: Research on Production Logistics System in Automobile Enterprise Based on Radio Frequency Identification. Logistics Sci-Tech. (1), 103105 (2007)

12. Wang, Y., Wan, C., Guo, Q., et al.: Towards developing a edible fungi factory production management system based on RFID technology. Transactions of the CSAE 24(2), 206-210 (2008)

13. Sperber, W.H.: HACCP does not work from Farm to Table. Food Control 16(2005), 511$514(2003)$

14. Wong, K.H.M., Hui, P.C.L., Chan, A.C.K.: Cryptography and authentication on RFID passive tags for apparel products. Computers in Industry, 342-349 (2006)

15. Wu, S.: Discussion on Some Problems in the Industrial Production of Edible Fungi. Edible Fungi of China 1, 52-54 (2008)

16. You, J.: Study on Supply Chain Oriented WIP Tracking and Management System. Nanjing University of Aeronautics and Astronautics, Beijing (2005) 